\title{
Blood Pressure Measurement in Different Outpatient Clinics
}

\author{
Ricardo Pereira Silva José Wellington Lima Raul Pinheiro Medeiros \\ Haroldo Heitor Ribeiro Filho Pedro Henrique de Oliveira Filgueira \\ Geraldo Bezerra da Silva, Jr. Ramon Rawache Barbosa de Lima \\ Carlos Roberto Martins Rodrigues Sobrinho \\ Division of Cardiology, Department of Internal Medicine, School of Medicine, Federal University of Ceara, \\ Fortaleza, Brazil
}

\section{Key Words}

Blood pressure $\cdot$ Hypertension · Measurement •

Cardiology $\cdot$ Medical specialty

\begin{abstract}
The objective of this study is to investigate how blood pressure is measured in different outpatient clinics. This is a retrospective study performed with 1,000 patients, randomly selected among patients followed in different outpatient clinics in Fortaleza, Brazil. Among the 1,000 patients, 962 had available records. The older the patient, the greater the possibility of having had blood pressure measured. In subsequent visits, blood pressure was measured more often than in the first visits. Blood pressure was measured more often among patients with chronic disease. The specialty with the highest proportion of blood pressure measurement was cardiology (85\%). At the surgery, dermatology and traumatology clinics, blood pressure was measured in less than $5 \%$ of visits, and at the ophthalmology, sexually transmitted diseases, psychiatry, proctology and otolaryngology clinics, blood pressure was not measured in any visit. Cardiology, endocrinology, nephrology, geriatrics and internal medicine
\end{abstract}

\section{KARGER}

Fax +41613061234 E-Mail karger@karger.ch www.karger.com
(C) 2010 S. Karger AG, Basel

$1420-4096 / 10 / 0333-0235 \$ 26.00 / 0$

Accessible online at: www.karger.com/kbr were the specialties where blood pressure was more frequently measured. It is important to measure blood pressure in any medical specialty in order to give early diagnosis of hypertension and provide adequate blood pressure control.

Copyright $\odot 2010$ S. Karger AG, Basel

\section{Introduction}

Blood pressure should be measured in every health evaluation by nurses and physicians in every medical specialty [1]. High blood pressure is very frequent in Brazil, as well as in the rest of the world, with a prevalence higher than $20 \%$ in adults and $50 \%$ in the elderly [2-4]. This is an important risk factor for coronary artery disease and may be an important cause of heart failure, chronic kidney disease and stroke. A Brazilian study showed that half of the patients did not know that they had high blood pressure, $60 \%$ of them were not receiving any treatment and only $10 \%$ had blood pressure adequately controlled [5].

Precise blood pressure measurement is essential for proper management. Equipment for blood pressure

Prof. Dr. Ricardo Pereira Silva

Rua República do Líbano 630/1002

Fortaleza, Ceara 60160-140 (Brazil)

E-Mail ricardops@secrel.com.br 
Table 1. Clinical characteristics of patients included in the study $(\mathrm{n}=962)$ for the evaluation of blood pressure measurement in a Brazilian teaching hospital in 2007

\begin{tabular}{lll}
\hline & \multicolumn{2}{l}{ Frequency } \\
\cline { 2 - 3 } & $\mathrm{n}$ & $\%$ \\
\hline Gender & & \\
$\quad$ Female & 629 & 65.4 \\
$\quad$ Male & 333 & 34.6 \\
Age & & \\
18-29 & 136 & 14.1 \\
30-39 & 134 & 13.9 \\
$40-49$ & 205 & 21.3 \\
50-59 & 190 & 19.8 \\
60-96 & 297 & 30.9 \\
Type of visit & & \\
$\quad$ First visit & 276 & 28.7 \\
Subsequent & 686 & 71.3 \\
Chronic diseases & & \\
Absent & 313 & 32.5 \\
Present & 649 & 67.5 \\
\hline
\end{tabular}

measurement may be aneroid, with mercury or electronic. Independently of the type, it should always be validated. The person who measures blood pressure should be well trained and the patient should be in the right position $[6,7]$. Patients should be calmly seated in a chair for at least $5 \mathrm{~min}$ before their blood pressure is measured, their feet should be placed on the floor and their arm where blood pressure will be measured should be at the height of the heart. Patients should not have any coffee and should refrain from smoking or physical exercise 30 min before blood pressure is measured. A cuff of appropriate size should be used. Two blood pressure measurements should be done and the average should be calculated [8].

Although blood pressure should be measured in every outpatient clinic, regardless of the physician's specialty, in practice it is not always done. Lessa et al. [9] studied the records of 1,084 patients on their first visit in 11 different clinical settings in Salvador city, Brazil, and they observed that blood pressure was measured in only $18.7 \%$ of cases. Posterior studies, after the implementation of the National Program of Education and Control of Hypertension found a blood pressure measure of $35.9 \%$, which is still less than the ideal [10]. The objective of this study is to assess how blood pressure is measured in different outpatient clinics in a large tertiary hospital.

\section{Methods}

This is a retrospective study performed with 1,000 randomly selected patients followed in different clinics at the Walter Cantidio University Hospital, Fortaleza, Brazil, in 2007. A research form was created for every patient including name, register number, gender, medical specialty, age and diagnosis. Patients were classified according to the medical specialty in which they were followed and the number of blood pressure measurements which were recorded. The specialties that had less than 10 visits in 2007 were not considered as visits, because the number was not enough to be included in the statistical analysis. Visits for digestive, vascular, thoracic and plastic surgery were termed as surgery outpatient clinics.

The main parameters studied here were the proportion of patients without blood pressure measurement at any medical visit and the proportion of patients without blood pressure measurement at the first visit. In a preliminary study with 100 patients, the proportion of patients who did not have blood pressure measured was $40 \%$ in some medical visits during follow-up and $30 \%$ at the first medical visit. For the estimation of the adequate sample size, the second parameter was considered. For the estimation of a proportion of $31 \%$ with a $95 \%$ CI with a $10 \%$ precision $(95 \%$ CI: 27.9-34.1\%), a sample size of at least 912 patients was required. For this reason, a randomized sample of 1,000 patients was considered for the present study.

For the statistical analysis, the prevalence and confidence interval of patients who did not have blood pressure measured at the first visit or in any other medical visit were estimated. Prevalence was analyzed according to gender, age, specialty and type of disease (acute or chronic). Proportions were compared by a $\chi^{2}$ test or Fisher's exact test.

\section{Results}

Among the 1,000 patients followed at the Walter Cantidio University Hospital outpatient clinics, 962 had available records. The majority of patients were female (65\%), had subsequent medical visits $(71 \%)$ and had chronic diseases (67.5\%; table 1).

These 962 patients had a total of 1,979 visits. There was no difference in blood pressure measurement when comparing patients according to gender. The older the patient, the greater the possibility of having had blood pressure measured. In subsequent visits, blood pressure was measured more often than in the first visits. Blood pressure was measured more often among patients with a chronic disease (table 2).

The majority of visits were done in the endocrinology clinics, where blood pressure was measured in $77 \%$ of the visits. The specialty with the highest proportion of blood pressure measurement was cardiology (85\%). At the surgery, dermatology and traumatology clinics, blood pressure was measured in less than $5 \%$ of visits, and at the 
Table 2. Association between the characteristics of the sample and the frequency of blood pressure measurement

\begin{tabular}{|c|c|c|c|c|}
\hline & \multirow[t]{2}{*}{ Total } & \multicolumn{2}{|c|}{$\begin{array}{l}\text { Specialty clinics where blood } \\
\text { pressure was measured }\end{array}$} & \multirow[t]{2}{*}{$\mathrm{p}$} \\
\hline & & $\mathrm{n}$ & $\%$ & \\
\hline \multicolumn{5}{|l|}{ Gender } \\
\hline Female & 1,287 & 574 & 39.0 & \\
\hline Male & 692 & 293 & 36.4 & 0.160 \\
\hline \multicolumn{5}{|l|}{ Age } \\
\hline $18-29$ & 231 & 69 & 29.2 & \\
\hline $30-39$ & 245 & 87 & 35.5 & \\
\hline $40-49$ & 442 & 165 & 37.3 & 0.0001 \\
\hline $50-59$ & 403 & 173 & 42.9 & \\
\hline $60-96$ & 658 & 297 & 45.1 & \\
\hline \multicolumn{5}{|l|}{ Type of visit } \\
\hline First & 284 & 72 & 23.2 & \\
\hline Subsequent & 1,991 & 795 & 43.2 & 0.0001 \\
\hline \multicolumn{5}{|c|}{ Chronic diseases } \\
\hline Absent & 403 & 44 & 10.9 & \\
\hline Present & 1,576 & 747 & 47.4 & 0.0001 \\
\hline
\end{tabular}

ophthalmology, sexually transmitted diseases, psychiatry, proctology and otolaryngology clinics, blood pressure was not measured at any visit (table 3 ).

Among the randomized patients, 276 had their first visit in 2007. There was no difference between gender and age for blood pressure measurement. The main factor for blood pressure measurement at the first visits was the presence of chronic diseases (table 4). Among these 276 first visits, the majority was at the ophthalmology clinics $(\mathrm{n}=37)$, where blood pressure was not measured at any time. Blood pressure was also not measured in the first visits at the traumatology and otolaryngology clinics. At the surgery, sexually transmitted diseases and dermatology clinics, blood pressure was measured in less than $10 \%$ of visits. At the internal medicine, gastroenterology, rheumatology, neurology, hematology and urology clinics, blood pressure was measured in less than half of the visits (table 5).

\section{Discussion}

The present study presents interesting facts related to blood pressure measurement. It was observed that the older the patient, the greater the probability of having had blood pressure measured. This probably occurred because it is well known that high blood pressure is more frequent in older than in young people. Blood pressure
Table 3. Blood pressure measurement during medical visits ( $\mathrm{n}=$ $1,979)$ with patients included in the study $(n=962)$ for the evaluation of blood pressure measurement in a Brazilian teaching hospital in 2007

\begin{tabular}{|c|c|c|c|}
\hline \multirow[t]{2}{*}{ Specialty } & \multirow[t]{2}{*}{$\begin{array}{l}\text { Total } \\
\text { visits }\end{array}$} & \multicolumn{2}{|c|}{$\begin{array}{l}\text { Visits in which blood } \\
\text { pressure was measured }\end{array}$} \\
\hline & & $\mathrm{n}$ & $\%$ \\
\hline Cardiology & 212 & 181 & 85.4 \\
\hline Endocrinology & 273 & 210 & 76.9 \\
\hline Nephrology & 74 & 49 & 66.2 \\
\hline Geriatrics & 24 & 15 & 62.5 \\
\hline Internal medicine & 43 & 26 & 60.5 \\
\hline Rheumatology & 218 & 116 & 53.2 \\
\hline Hematology & 180 & 94 & 52.2 \\
\hline Gastroenterology & 102 & 41 & 40.2 \\
\hline Pneumology & 55 & 21 & 38.2 \\
\hline Infectology & 26 & 5 & 19.2 \\
\hline Hepatic transplantation & 41 & 6 & 14.6 \\
\hline Urology & 46 & 6 & 13 \\
\hline Neurology & 129 & 12 & 9.3 \\
\hline Traumatology & 76 & 3 & 3.9 \\
\hline Dermatology & 91 & 3 & 3.3 \\
\hline Surgery & 130 & 2 & 1.5 \\
\hline Otolaryngology & 51 & 0 & 0 \\
\hline Coloproctology & 34 & 0 & 0 \\
\hline Ophthalmology & 133 & 0 & 0 \\
\hline Sexually transmitted diseases & 25 & 0 & 0 \\
\hline Psychiatry & 10 & 0 & 0 \\
\hline Others $^{1}$ & 6 & 1 & 16.7 \\
\hline Total & 1,979 & 791 & 40 \\
\hline
\end{tabular}

${ }^{1}$ Renal transplantation (3), oncology (2) and gynecology (1).

Table 4. Association between the characteristics of the sample and the frequency of blood pressure measurement at the first medical visit

\begin{tabular}{|c|c|c|c|c|}
\hline & \multirow[t]{2}{*}{ Total } & \multicolumn{2}{|c|}{$\begin{array}{l}\text { Visits in which blood } \\
\text { pressure was measured }\end{array}$} & \multirow[t]{2}{*}{$\mathrm{p}$} \\
\hline & & $\mathrm{n}$ & $\%$ & \\
\hline \multicolumn{5}{|l|}{ Gender } \\
\hline Female & 170 & 40 & 23.5 & \\
\hline Male & 106 & 27 & 25.5 & 0.714 \\
\hline \multicolumn{5}{|l|}{ Age } \\
\hline $18-29$ & 58 & 12 & 20.7 & \\
\hline $30-39$ & 46 & 15 & 32.6 & \\
\hline $40-49$ & 59 & 12 & 20.3 & 0.504 \\
\hline $50-59$ & 49 & 14 & 28.6 & \\
\hline $60-96$ & 64 & 14 & 21.9 & \\
\hline \multicolumn{5}{|c|}{ Chronic diseases } \\
\hline Absent & 166 & 24 & 14.5 & \\
\hline Present & 110 & 43 & 39.1 & 0.0001 \\
\hline
\end{tabular}


Table 5. Blood pressure measurement during the first medical visit in patients included in the study $(n=962)$ for the evaluation of blood pressure measurement in a Brazilian teaching hospital in 2007

\begin{tabular}{lccc}
\hline Specialty & $\begin{array}{r}\text { Total } \\
\text { visits }\end{array}$ & \multicolumn{2}{c}{$\begin{array}{c}\text { Visits in which blood } \\
\text { pressure was measured }\end{array}$} \\
\cline { 3 - 4 } & & $\mathrm{n}$ & $\%$ \\
\hline Endocrinology & 7 & 6 & 85.7 \\
Cardiology & 9 & 7 & 77.8 \\
Nephrology & 10 & 7 & 70 \\
Pneumology & 13 & 6 & 46.2 \\
Rheumatology & 16 & 7 & 43.8 \\
Internal medicine & 7 & 3 & 42.9 \\
Hematology & 25 & 9 & 36 \\
Gastroenterology & 14 & 5 & 35.7 \\
Neurology & 28 & 8 & 28.6 \\
Urology & 11 & 2 & 18.2 \\
Sexually transmitted diseases & 12 & 1 & 8.3 \\
Dermatology & 18 & 1 & 5.6 \\
Surgery & 20 & 1 & 5 \\
Otolaryngology & 13 & 0 & 0 \\
Traumatology & 24 & 0 & 0 \\
Ophthalmology & 37 & 0 & 0 \\
Other & 12 & 4 & 33.3 \\
\hline Total & 276 & 67 & 24.3 \\
\hline
\end{tabular}

${ }^{1}$ Geriatrics (4), coloproctology (4), infectology (3) and hepatic transplantation (1).

was also more frequently measured in patients with chronic diseases because it is also well known that patients with chronic diseases, such as diabetes, have a greater probability of having hypertension than the general population; therefore, physicians in general have a higher concern about hypertension in this group of patients. Blood pressure was more frequently measured in cardiology, endocrinology and nephrology clinics, which is evidence of the careful approach of the physicians of these specialties in investigating and treating hypertension. Even patients without anti-hypertensive treatment should have their blood pressure measured because it is important to investigate hypertension in every patient who seeks medical care.

It is also important to consider anti-hypertensive treatment. We have observed that blood pressure is not always measured during the medical visits, even among patients with hypertension. The lack of aggressive treatment for high blood pressure leads to the development of complications related to target organ damage. Further studies are required to assess the impact of measuring blood pressure more frequently and providing a more aggressive treatment of hypertension in the outcome of these patients.

In general, there is a very low incidence of blood pressure measurement at our hospital. As this is a teaching hospital, we expected that the proportion of visits with blood pressure measurement would be greater than what was observed. There was an important difference in the incidence of blood pressure measurement when comparing the different specialties. In cardiology, endocrinology, nephrology, geriatrics and internal medicine clinics, blood pressure was measured in more than $65 \%$ of visits, while in surgery, dermatology and traumatology, blood pressure was measured in less than $5 \%$ of visits. In proctology, ophthalmology, sexually transmitted diseases, psychiatry and otolaryngology clinics, it was not measured at all. Although cardiology clinics had the greatest incidence of blood pressure measurement (85\%), this is not enough as blood pressure should be measured at all visits in this specialty.

The only national research about this theme was done by Lessa et al. [9], in Salvador city. These researchers included only first visits. When we compared our data with other studies, we observed that in endocrinology, cardiology, rheumatology, hematology, gastroenterology, nephrology and pneumology clinics, the incidence of blood pressure measurement was greater, but in ophthalmology, neurology, surgery, dermatology, traumatology, otolaryngology and sexually transmitted diseases clinics, the incidence of blood pressure measurement was lower than in the study by Lessa et al. It is important to note that the research by Lessa et al. was done in different places of health care attention and ours was done in only one hospital, where it was expected to find a higher incidence of blood pressure measurement.

A hypothesis to explain the low incidence of blood pressure measurement may be the fact that in some visits blood pressure was measured but not registered. Another hypothesis is that if the patient has his blood pressure measured regularly in another office (e.g. cardiology), the physician of another specialty thinks that blood pressure does not need to be measured again.

Hypertension diagnosis may be done in a simple and cheap manner. It is enough when someone regularly measures blood pressure at all visits. Hypertension has a great prevalence and it may be dangerous for the heart, kidneys and central nervous system. Therefore, it is important to have the diagnosis as soon as possible and to measure blood pressure at every medical visit, independently of the specialty or the purpose of the visit. 


\section{References}

1 Brazilian Society of Cardiology: V Diretrizes Brasileiras de Hipertensão Arterial 2006. http://www.sbn.org.br/Diretrizes/V_Diretrizes_Brasileiras_de_Hipertensao_Arterial.pdf.

2 Brazilian Society of Cardiology: IV Brazilian Guidelines in Arterial Hypertension. Arq Bras Cardiol 2004;82(Suppl 4):7-22.

- 3 Gus I, Harzheim E, Zaslavsky C, Medina C, Gus M: Prevalence, awareness and control of systemic arterial hypertension in the state of Rio Grande do Sul. Arq Bras Cardiol 2004; 83:429-433.
4 Matos AC, Ladeia AM: Assessment of cardiovascular risk factors in a rural community in the Brazilian state of Bahia. Arq Bras Cardiol 2003;81:297-302.

5 Firmo JO, Barreto SM, Lima-Costa MF: The Bambui Health and aging study (BHAS): factors associated with the treatment of hypertension in older adults in the community. Cad Saúde Pública 2003;19:817-827.

- 6 Perloff D, Grim C, Flack J, et al: Human blood pressure determination by sphygmomanometry. Circulation 1993;88:24602470.

-7 Gerin W, Schwartz AR, Pickering TG, et al Limitations of current validation protocols for home blood pressure monitors for individual patients. Blood Press Monit 2007;7: 313-318.
8 Chobanian A, Bakris G, Black HR, et al: Seventh report of the Joint National Committee on Prevention, Detection, Evaluation and Treatment of High Blood Pressure. Hypertension 2003;42:1206-1252.

9 Lessa IC, Cortes E, Menezes C, et al: A medida da tensão arterial na prática médica de rotina. Rev Assoc Med Brasil 1984;30:50-52.

$>10$ Lessa IC, Daltro ME: Diferenças na medida da pressão arterial em primeiras consultas pré e pós-implantação no Programa Nacional de Controle da Hipertensão. Rev Assoc Med Brasil 1993;39:141-145. 